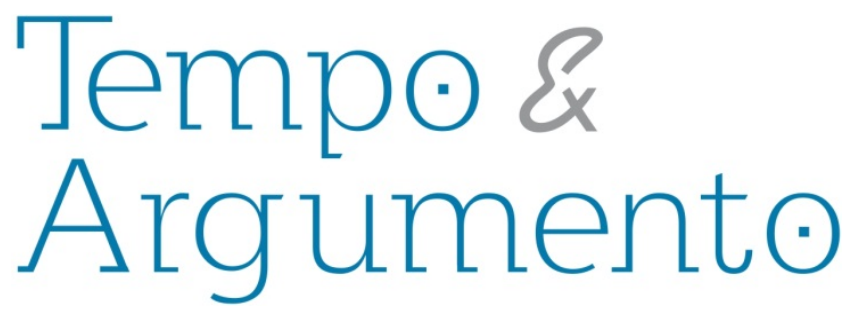

\title{
Um acervo como ponto de partida
}

\section{Resumo}

Abrir velhos baús de memórias significa, muitas vezes, um reencontro com a própria vida. Os papéis amarelados pelo tempo guardam segredos, emoções, sonhos, expectativas, projetos, costumes e práticas (CUNHA, 2009). Nessa perspectiva, o presente artigo tem como objetivo apresentar de que forma se realizou o encontro com o arquivo pessoal de Astrogildes Delgado de Carvalho, educadora que atuou nas décadas de 1930 a 1980, no Rio de Janeiro. Sua ação influenciou a prática da educação infantil e a formação de educadoras dos centros de atendimento ao pré-escolar (Capes), juntamente com a Organização Mundial para a Educação Pré-escolar/Brasil/Rio de Janeiro (Omep/BR/RJ). Além disso, tem-se como objetivo perceber de que maneira esse encontro possibilitou a realização da pesquisa biográfica sobre a educadora.

Palavras-chave: Coleções Particulares; Educação de Crianças; Carvalho, Astrogildes Delgado de - Biografia.

\section{Luisa Maria Delgado de Carvalho}

Doutora em História pela Universidade do Estado do Rio de Janeiro. Possui formação em história da educação e é professora na Universidade do Estado do Rio de Janeiro. Brasil ludelgad@gmail.com

\section{Para citar este artigo:}

CARVALHO, Luisa Maria Delgado de. Um acervo como ponto de partida. Revista Tempo e Argumento, Florianópolis, v. 7, n.14, p. 217 - 234. jan./abr. 2015.

\section{DOI: $10.5965 / 2175180307142015217$}

http://dx.doi.org/10.5965/2175180307142015217 


\title{
A collection as a starting point
}

\begin{abstract}
To open old trunks of memories often means a reunion with our own life. The yellowed papers by the time keep secrets, emotions, dreams, expectations, projects, customs and practices (CUNHA, 2009). From this perspective, this article aims to present the way occurred the research on Astrogildes Delgado de Carvalho files. She was an educator who served in the decades from 1930 to 1980 , in Rio de Janeiro. Her action influenced the practice of early childhood education and the training of teachers of call centers to preschool (Capes), along with the World Organization for Preschool Education / Brazil / Rio de Janeiro (Omep/BR/RJ). In addition, the objective is to realize how this meeting enabled the realization of biographical research on the teacher.
\end{abstract}

Keywords: Private Collections; Children's education; Carvalho, Astrogildes Delgado - Biography

Cartas e diários pessoais são documentos que carregam traços ritualísticos, consagrando-se tanto como artefatos culturais quanto como fontes, que têm, para o historiador, outro estatuto: abrir espaço a partir do qual a história pode ser investigada, isto é, buscada em vestígios. Por muito tempo esquecidas, guardadas, silenciosamente escondidas em baús e caixas, estas fontes despertam o interesse do historiador e querem se fazer ouvir.

Maria Teresa Santos Cunha 
O presente artigo é resultado da pesquisa de doutorado realizada entre os anos de 2010 e 2014, na área de conhecimento da história da educação, sobre a trajetória profissional da educadora Astrogildes Delgado de Carvalho, que iniciou suas práticas educacionais em 1931 e as encerrou na década de 1980.

A educadora em questão, católica militante, praticamente desconhecida no campo educacional, desenvolveu importantes ações que tinham como foco, de modo particular, a educação infantil, área pouco valorizada nos primeiros tempos de seu trabalho como educadora. Astrogildes destacou-se na educação de Petrópolis-RJ, principalmente pela fundação da Escola Chapelinho Vermelho e sua atuação nela e no Externato Delgado de Carvalho. Posteriormente, ingressou na Organização Mundial de Educação Pré-escolar (Omep) e atuou como formadora de educadoras e como responsável pelos centros de atendimento ao pré-escolar (Capes), criados pela instituição, em localidades habitadas por populações menos favorecidas.

A pesquisa se apoiou em base documental diversificada, incluindo, de modo valorizado, o acervo pessoal da educadora. Houve um cuidado em dar destaque a vozes, papéis, memórias vivas e deslindar os fios que foram sendo tecidos ao longo desses anos, valorizando a participação de Astrogildes Delgado de Carvalho na promoção e garantia dos direitos da criança de zero a seis anos.

Os registros de experiências pessoais conservadas pela escrita, segundo Maria Teresa Cunha (2009), estão, quase sempre, relegados à invisibilidade - em velhos baús, queimados ou jogados no lixo -, dado seu caráter de “escritas ordinárias". Se protegidos em acervos pessoais, formam um corpo documental de inestimável valor como fonte histórica e podem fornecer informações e indícios sobre práticas cotidianas expressas em hábitos, costumes, valores e representações de uma época e, como tais, analisados a partir do conceito de "lugares de memória" (ALBERCA apud CUNHA, 2009).

Ângela Castro Gomes, em seu artigo Nas malhas do Feitiço, o historiador e os encantos dos arquivos (2004), ressalta que a descoberta dos arquivos privados está relacionada a uma significativa transformação no campo historiográfico, do qual 

importante a escrita de si.

Para a pesquisadora, nos últimos dez anos, houve uma espécie de boom de publicações de caráter biográfico e autobiográfico, devido, em grande parte, ao interesse pelo gênero dos escritos - uma escrita de si (GOMES, 2004, p. 8). Embora tal documentação venha sendo usada como fonte, apenas recentemente foi considerada privilegiada, vindo a se tornar, ela própria, objeto de pesquisa. É importante sinalizar que as pesquisas sobre escritas de si vêm sendo crescentemente valorizadas, de forma particular no campo da história da educação. A autora ainda ressalta a necessidade de maior investimento em sua utilização e análise e maior cuidado em termos de procedimentos teórico-metodológicos.

Ângela Castro Gomes (2004) chama a atenção para a necessidade de se criarem centros de pesquisa e documentação destinados à guarda de arquivos privados/pessoais, tanto de homens públicos, quanto de homens comuns. A utilização desse tipo de material arquivístico estimula e, ao mesmo tempo, permite a sistematização de conhecimentos e o uso de metodologias referentes à sua guarda e ao seu uso como fonte histórica.

O interesse por arquivos privados e pela escrita de si, portanto, vem ganhando terreno no trabalho de muitos historiadores do país, ilustrando as várias possibilidades de se lidar com esse tipo de material. Pesquisas com esse foco permitem a reconstituição de uma memória de si, realizada pelo recolhimento de objetos materiais, com ou sem intenção de resultarem em coleções. Fotografias, cartões postais, objetos cotidianos transformam o espaço privado da casa em um "teatro de memória". As práticas da escrita de si possibilitam evidenciar, com clareza, uma trajetória individual, que tem um percurso, que se altera ao longo do tempo, que decorre por sucessão. Nesta perspectiva, a vida de uma pessoa pode ser "decomposta" em tempos e ritmos diversos: um tempo de casa, um tempo de trabalho, etc. Para a pesquisadora, 0 indivíduo que postula uma identidade para si e busca registrar sua vida não é mais 

permitem o registro de sua identidade, o fotografar e escrever abriu espaço para a legitimidade do desejo de registrar a memória do homem anônimo, do indivíduo comum, da professora, cuja vida é composta de fatos e acontecimentos cotidianos, mas importantes para a produção de si. Os registros de memória dos indivíduos modernos são, portanto, de forma geral, subjetivos, fragmentados e ordinários como suas vidas (GOMES, 2004, p. 11-13).

A valorização de biografias, autobiografias e escritas de si em particular, em suas diferentes formas, tem relação com o florescimento da história cultural, procurando dar especial atenção às questões de gênero. É importante dizer que, nesse tipo de escrita, se têm valorizado arquivos de mulheres, em especial de professoras. Os estudos da micro-história, que considera a variação de escala entre o indivíduo e a sociedade, também têm dado valor crescente às histórias de vida. Nessa "nova" história cultural, podem-se incluir as abordagens de uma "história social das ideias", de uma "história da cultura" de forte referencial antropológico e também daquilo que, na França, se chama "história de intelectuais", mais centrada nas elites culturais e em sua dinâmica de sociabilidade. Os conceitos que povoam essa grande e diversificada área de trabalho vêm de diferentes autores, com diferentes visões de mundo; "habitus; circulação de ideias; apropriação cultural; tradição e sociabilidade intelectuais; experiência; projeto e campo de possibilidades; geração, trajetória e biografia, dentre alguns que se podem destacar" (GOMES, 2004. p. 123). A revalorização dos arquivos privados está, portanto, relacionada a um novo olhar para o indivíduo na história e na revalorização de suas ações. No entanto, a utilização da escrita de si, como fonte de pesquisa pelos historiadores, tem sido objeto de preocupação, gerando amplos debates sobre seu uso como fonte. Pierre Bourdieu (2011) chama a atenção para a “ilusão biográfica”, ou seja, para a falácia de se considerar uma vida como "[...] um todo, um conjunto coerente e orientado, que pode e deve ser apreendido como expressão unitária de uma 'intenção’ subjetiva e objetiva, de um projeto [...]” (p. 
184). A pesquisadora Ângela Castro Gomes (2004), dialogando com Bourdieu, adverte que a ideia de "ilusão biográfica" chama a atenção para a ingenuidade de se supor existir "um eu" coerente e contínuo, que se revelaria nesse tipo de escrita, exatamente pelo efeito de verdade que ela seria capaz de produzir.

Segundo a mesma autora, o "grande feitiço do arquivo privado" se encontra no fato de guardar uma documentação pessoal, produzida com a marca da personalidade e não destinada explicitamente ao espaço público, revelando-se, seu produtor, de forma "verdadeira": aí ele se mostraria "de fato", o que seria atestado pela espontaneidade e pela intimidade que marcam boa parte dos registros. A documentação dos arquivos privados permitiria, de forma particular, dar vida à história de vida de indivíduos, com suas virtudes e defeitos, que se revelariam nesse tipo de material (GOMES, 2004).

Arlete Farge (2009) lembra que o acervo nasce da desordem e também supõe mãos que manipulam e classificam os documentos, olhos que vigiam o escrito, cheiros que despertam memórias. Observa, ainda, que os escritos privados, que jaziam no fundo dos armários ou nos sótãos, com isso ganham “vida”. O real do arquivo tornase não apenas vestígio, mas igualmente mantém ordenação de figuras da realidade e infinitas relações com o real (FARGE, 2009, p. 35).

Assim, com curiosidade, fui ao encontro do arquivo, numa tentativa de me aproximar desse real que se encontrava presente e que iria me auxiliar a construir a trajetória profissional de Astrogildes Delgado de Carvalho, indissociável, por sua vez, da dimensão privada de sua vida. A cada nova descoberta, porém, tentava manter o olhar de historiadora mediando minha relação pessoal e profissional com Didinha, para não cair numa armadilha e aceitar tudo como expressão da verdade, postura, aliás, que se deve tomar diante de qualquer documento.

Mas, como diz Gomes (2004), os arquivos pessoais, os materiais que os compõem podem exercer sedução. No caso de um arquivo privado de uma pessoa com tanta proximidade, temos que tomar um cuidado maior, de forma a não cair na armadilha do que o documento apresenta. 
O encontro com o seu acervo veio confirmar o que Arlette Farge identifica, em seu livro O sabor do arquivo:

Conjunto de documentos, quaisquer que sejam suas formas ou seu suporte material, cujo crescimento se deu de forma orgânica, automática, no exercício das atividades de uma pessoa física ou jurídica, privada ou pública, e cuja conservação respeita esse crescimento sem jamais desmembrá-lo (FARGE, 2009, p. 12).

Parafraseando a autora, posso afirmar que o arquivo traz possibilidades de focalizar instantes da vida de personagens comuns; agindo como um desnudamento, encolhidos em algumas linhas, aparece não apenas o inacessível, como também o vivo: "Fragmentos de verdade até então retidos saltam à vista; ofuscantes de nitidez e credibilidade."1

Os documentos guardados, segundo Giovanaz (1999), representam ou nos contam a experiência vivida do sujeito que, durante algum tempo, os acumulou. Esses documentos podem significar uma necessidade de estar no mundo e também um desejo de continuar existindo além do tempo real da vida. Para a pesquisadora Ângela Castro Gomes (2004), os documentos pessoais permitem uma espécie de contato muito próximo com os sujeitos da história que pesquisamos. Neles, "nossos" atores aparecem de forma fantasticamente "real" e sem disfarces. Nós, historiadores, podemos passar a conhecê-los na "intimidade de seus sentimentos e nos surpreendermos a dialogar com eles e até imaginar pensamentos" (GOMES, 2004 p. 126). No entanto, quando vamos ao encontro do arquivo, percebemos que nem tudo "se guarda". Existe um processo seletivo, que, segundo Celso Castro:

Resulta diretamente da pessoa que define, em diferentes momentos, certos materiais e não outros e também como coisas que vale a pena guardar. O documento, portanto, não pré-existe ao arquivo: um determinado artefato se constitui em documento na medida em que é associado, por diferentes pessoas, a uma série de concepções de valor, memória e passado que o levam a ser preservado (CASTRO, 2005, p. 29).

\footnotetext{
${ }^{1}$ FARGE, ibid.
} 
Isto obedece à lógica da acumulação, nem sempre consensual entre os responsáveis pelo arquivo: por que guardar e onde guardar? Esse processo seletivo, como em qualquer caso, também esteve presente no arquivo de Didinha.

O mesmo pesquisador chama a atenção para outra questão: deve-se evitar um olhar naturalizado a respeito dos documentos nos quais a vida de uma instituição ou pessoa se encontra “objetivada". No que foi preservado, há sempre intenções variadas e da própria pessoa, que, ao longo de sua vida, realizou a seleção e determinou o que era ou não relevante guardar. $\mathrm{O}$ arquivo revela a intencionalidade de quem o produziu e, por outro lado, de quem organizou e guardou, mesmo quando o arquivo parece ter sido simplesmente deixado "do jeito que estava", sem qualquer cuidado (CASTRO, 2005).

Como escreve o historiador espanhol António Castillo Gómez:

Não há dúvidas da importância que têm os arquivos que guardam a memória institucional ou do poder, habituais espaços do historiador, mas tampouco se deve duvidar da utilidade que oferecem as escrituras das pessoas comuns. Através delas, abre-se a possibilidade de (re)conhecer outras maneiras de viver e de narrar o vivido. Com elas, enfim, devolvemos uma certa visibilidade a muitos protagonistas anônimos do acontecer coletivo (apud CUNHA, 2007, p. 68).

No caso específico de documentos do universo feminino, Ana Chystina Mignot (2002), em sua tese de doutorado sobre Armanda Álvaro Alberto, observa que, diferentemente dos arquivos públicos, nos quais, com frequência, as mulheres não tinham voz, os arquivos privados não apenas nos fornecem informações sobre o cotidiano delas, como também nos permitem ver o mundo através de experiências comuns. Encontramos neles pequeninas relíquias que trazem muitas lembranças. $O$ arquivo de Didinha simboliza lembranças e memórias de sua vida, que agora irão me fornecer, como pesquisadora, dados para compreender outros tempos e construir um estudo biográfico. 


\section{O encontro com o arquivo}

Em meu encontro com o arquivo, pude perceber que os materiais nele contidos forneciam valiosos indícios sobre a educadora, o que provocou meu interesse em desenvolver uma pesquisa sobre seu percurso profissional, tendo como foco, em particular, as práticas pedagógicas que ela desenvolveu em espaços voltados à educação infantil.

O trabalho de organização do acervo por ela deixado teve início com a chegada de materiais pessoais da educadora em minha casa, em 2003. Parte desses materiais estava guardada na sede da Organização Mundial de Ensino Pré-Escolar (Omep/Rio de Janeiro) desde a década de 1990, quando Didinha faleceu, e sua família doou a essa entidade o material relacionado ao trabalho que ela havia desenvolvido na Omep das décadas de 1960 a 1980. Além desse material, encontrei nos arquivos da sede dessa organização documentos, relatórios oficiais, entre outros, que foram digitalizados e catalogados.

Em posse de toda essa documentação, percebi ter em meu poder um acervo com informações importantes para a pesquisa. Ao longo desses quatro anos de estudo no curso de doutorado, sem pressa e meticulosamente, fui examinando, experimentando e saboreando cada documento que mostrava o quanto o arquivo falava de Didinha e o quanto se "fazia falar". Assim, ia procurando retirar, de cada fragmento de frases encontradas, "a emoção que é um instrumento a mais para polir a pedra do passado e do silêncio" (FARGE, 2009, p. 15).

A cada encontro, a cada descoberta, o arquivo ia me oferecendo um esboço vivo do caminho por ela percorrido, mostrando sua inserção na vida social de Petrópolis, seus hábitos e costumes do período de sua adolescência. Sua vida profissional e cotidiana estava ali impressa. Sentia-me uma "descobridora", ou melhor, uma exploradora no sentido "arqueológico".

Todos os materiais foram digitalizados e salvos em pastas. Algumas transparências precisaram ser retocadas, em função das letras apagadas pelo tempo. Foi interessante perceber que a documentação relacionada às questões pedagógicas, 
pela própria Didinha. Após este processo, os materiais foram arquivados em pastas, em folhas plásticas, para possibilitar seu manuseio sem os danificar. Cada material recebeu uma etiqueta com um código. A cada pasta finalizada, criei um sumário com os códigos para melhor localizá-los.

Construí duas catalogações diferenciadas, uma, destinada às cartas; a outra, às fotos. Preparei uma ficha de identificação ${ }^{2}$ para o material de cada catalogação, na qual anotei as informações mais relevantes das fotos, como data, pessoas retratadas, local, assunto. Organizei a tabela de cartas conforme as décadas, seguida da separação entre destinatários e remetentes.

A partir desse primeiro encontro com o acervo, pude perceber que existia uma quantidade razoável de documentos ordinários. O arquivo de Didinha, à semelhança de outros arquivos femininos, era formado por diplomas, certificados, cadernos pessoais, cadernos de estudos dirigidos, cadernos religiosos, transparências, apostilas, livro manuscrito, fotografias, cartões, cadernos de recordações, álbuns de fotografias da família, livros de receitas, livros de poesias, maços de cartas, diários. Neste sentido, seu acervo se constitui em lugar de memória, como aqueles em que as mulheres revelam suas experiências, organizam o sentido da vida, elaboram vivências, testemunham práticas cotidianas, costumes e hábitos, explicam, ensinam, constroem, reconstroem suas vidas, lançando um olhar sobre si mesmas, sobre o espaço doméstico, as famílias, a sociedade. Seus legados permitem leituras diversas, fazendo emergir o engajamento social e de classe de suas produtoras (MALUF, 1996 apud MIGNOT, 2002, p. 83). Uma vez realizado o levantamento do acervo completo, elaborei

\footnotetext{
${ }^{2}$ Utilizei essa metodologia a partir de conhecimentos adquiridos na disciplina ministrada por Anna Chrystina Mignot e Marcia Cabral, em Memória Escrita e Narrativas (2011), além de leituras específicas como Mauad (2008), e da participação em um minicurso, intitulado História da Cultura Escrita e História da Educação: Olhares para os Papéis da Escola, no IV Congresso Brasileiro de Educação, no Espírito Santo (maio. 2011).
} 
De posse de todo esse material arquivístico, iniciei uma leitura preliminar para saber o que continha cada caixa, procurando não tirar da ordem organizada por Didinha. Cada caixa aberta era para mim uma surpresa. Ela continha parte de sua vida. Eram papéis amarelados pelo tempo que, por muitos anos, testemunharam sua trajetória, do seu nascimento à sua morte. Sua memória deixava claro que o tempo possui ritmos e conteúdos diferenciados, na diacronia e na sincronia, e não pode ser entendido como linear, único e progressivo (GOMES, 2004). Pude perceber que, no acervo de Astrogildes, a sua vida, em todos os níveis, estava ali silenciada, escondida. Somente a partir de sua abertura fui percebendo a dimensão de seu trabalho como educadora e formadora de gerações de alunos e professores, assim como sua importância para o campo da educação infantil. Depois de reconhecido, visto e catalogado todo o material, selecionei o que iria utilizar para construir uma biografia possível!

\section{Fotografias: lembranças de uma vida}

Dentre os documentos que fazem parte do acervo de Didinha, encontrei um número expressivo de fotografias, com registros sobre o período vivido após sua chegada a Petrópolis e sua entrada no Colégio Santa Isabel, a partir de 1926. Algumas fotos estavam em álbuns organizados em momentos diversos de sua vida. Elas revelavam sua vida escolar, sua juventude na sociedade de Petrópolis, os eventos relativos às escolas que criou - a Chapelinho Vermelho (1948-1966) e o Externato Delgado de Carvalho (1961-1966) - e o período em que trabalhou na Omep (1968-1990). Ao me deparar com esse acervo de fotografias, compreendi que teria de levar em conta o quanto a imagem é em si objeto carregado de história e o quanto exige de reflexão sobre suas características, por sua linguagem particular sobre os acontecimentos. 
A pesquisadora Ana Mauad (2008) assinala que a prática de fotografar nossos filhos, nossos momentos importantes e os não-significativos faz parte de nossa vida. Mostra, ainda, em suas pesquisas, que a fotografia remete à memória, apresentando-se como marca da existência da pessoa e dos fatos vividos por ela. A leitura dos trabalhos dessa autora permitiu-me ampliar as reflexões a respeito da fotografia, percebendo o quanto de sentido ela fornece às experiências sociais e, ao mesmo tempo, as dignifica e hierarquiza, tornando-as memoráveis. Mauad (2008), em seu livro Poses e flagrantes, anota que "não se fotografa qualquer coisa, e a escolha do que será fotografado segue alguns protocolos que são perpassados pelas experiências sociais compartilhadas" (p. 19).

Ainda segundo a pesquisadora (2005), "as imagens técnicas, em especial a fotografia, devem ser trabalhadas a partir da ampliação da noção de testemunho". Afirma, também, que as “imagens contam histórias, fatos, acontecimentos, atualizam memória, inventam vivências e imaginam histórias " (MAUAD, p. 134). Parafraseando Le Goff, ela entende a fotografia simultaneamente como imagem-documento e como imagem-monumento. No primeiro caso, a fotografia seria "índice", marca de uma materialidade passada, na qual objetos, pessoas, lugares informam sobre determinados aspectos do passado. No segundo caso, a fotografia é "símbolo", aquilo que a sociedade estabeleceu como imagem a ser perenizada para o futuro, podendo-se, desse modo, entender que a fotografia, ao mesmo tempo em que informa, também conforma uma determinada visão de mundo (MAUAD, 2005, p. 73-78).

\section{Cadernos... Marcas de uma época}

Os variados cadernos possibilitaram aferir a diversidade de temas dos quais a educadora, em diferentes momentos de sua trajetória pessoal e profissional, se aproximou. Os primeiros cadernos, datados das décadas de 1930 a 1950, estão direcionados à escrita da vida familiar, o que vem confirmar o que diz Mignot (2000, p. 21), em seu livro Papéis guardados: “no espaço doméstico, a escrita tem seu lugar privilegiado, procurando servir à construção da memória doméstica”. Para Didinha: 
A mulher deve ser tudo no lar. Serena em suas atitudes. Pronta a dar em todas as horas, mesmo ao receber uma ingratidão, mesmo incompreendida, sorrir e acalmar as tempestades com suas orações, e com sua paciência "dar a luz" as almas de seus filhos. Saber inocular, cultivar as flores que tem ao seu cuidado. Saber sorrir ao marido depois de uma ofensa para que ele, embora não dizendo, admire a religião que ensina sua mulher ser tão boa e santa. Chamar a atenção de seu marido para o que ofende a Deus e vai contra a finalidade do matrimônio, com caridade, mas com firmeza. Com os empregados doçura e caridade, desculpar sempre como faz Nossa Senhora conosco. Ensinar outra vez. Ter com eles a paciência que quereríamos que tivessem $\operatorname{conosco}^{3}$ (CARVALHO, 1953) $)^{4}$.

Nessa reflexão, podemos perceber as marcas da religiosidade católica na construção dos papéis sociais que ela desempenhava: os de mulher cristã, mãe e esposa.

Nesses cadernos, Didinha registrou poemas, memórias, ao lado de contas a pagar, listas de compras a serem feitas, assim como anotações de recados.

A escrita tem seu lugar privilegiado, pois possibilita tecer a memória da família, numa determinada época. Os cadernos, bilhetes, guardados por pessoas comuns significam, segundo Mignot, "iluminar a escrita ordinária". Artesanalmente confeccionados ou vendidos em livrarias, esses cadernos marcam ritos de passagem, nos quais o universo doméstico é palco de encenações. Para a autora, olhar papéis guardados por pessoas comuns - neste caso, folhear o caderno - é um convite para leituras diversas. Trata-se de fios que tecem a memória de uma família, uma instituição, uma época (MIGNOT, 2002, p. 21).

Para os pesquisadores, manuseá-los significa iluminar a escrita ordinária dos incontáveis atores que se utilizam de suas folhas, linhas ou margens. São papéis que fornecem algumas pistas passíveis de investigação sobre a escrita íntima, despertando relações entre memória, escrita, sociabilidades, redes de poder, cotidianos, cultura escrita e arquivamento. A mesma autora discute a historicidade desse suporte de escrita

\footnotetext{
${ }^{3}$ Foi mantida a grafia original em todas as citações de documentos primários.

${ }^{4} 2^{a}$ Conferência: o lar. Retiro Espiritual das mães cristãs, Colégio Nossa Senhora de Sion.
} 

de história.

\section{O encontro com as cartas}

Em meio aos materiais utilizados na pesquisa, destacam-se as correspondências ativas e passivas entre Didinha e o historiador Carlos Delgado de Carvalho. No universo de 90 correspondências que compõem o acervo de escritas epistolares de Didinha, selecionei o conjunto que mais me chamou a atenção. Este conjunto envolve as correspondências motivadas, além das questões familiares, pela relação construída entre ambos. Em 27 anos (1947-1967), foram trocadas 24 cartas, dois cartões e um telegrama de pêsames entre ambos.

Com a catalogação do arquivo, observei cuidadosamente que, nas primeiras cartas, datadas de 1940, Didinha, recém-casada, começava a construir seu diálogo com o casal Delgado de Carvalho, que, nesse período, estava fora do país. Coube ao seu filho, Carlos Alberto, marido de Didinha, acompanhar as obras de seu apartamento em Copacabana, e à nora, a comunicação através de missivas. Foi a partir dessa relação epistolar que os laços entre Didinha e Delgado de Carvalho foram se tecendo como uma relação afetuosa e paternal.

Segundo Maria Teresa Cunha (2007), a forma e o modo como as cartas são escritas e as condições de sua produção permitem encontrar uma história de sujeitos que se constroem e inventam pela escrita, uma possibilidade de "capturar sensibilidades do passado, através dos traços objetivos que estas deixaram para o presente" (CUNHA, 2007, p. 25 ).

Para Veronica Blas (2003), as cartas dirigidas às famílias e amigos são as que mais apresentaram mudanças desde o final do século XIX. Passaram a assumir novas funções, de acordo com as mudanças sociais e a partir do desenvolvimento de um novo sistema de ideias e valores. Em um novo contexto, as cartas familiares foram 
independentemente de idade, sexo ou classe social. A linguagem presente nas cartas tornou-se mais acessível a todos e, portanto, facilitou a comunicação social.

Nota-se, com o passar dos anos, que a relação construída entre Carlos Delgado de Carvalho e Didinha se estreitou. Esse laço se refletiu nas correspondências que passaram de uma escrita formal a uma escrita mais íntima e carinhosa. Nas cartas datadas do ano de 1940, percebe-se não só a mudança de tratamento do sogro, Carlos Delgado de Carvalho, destinatário, como também de assunto, que passaram a ser mais íntimos, relatados com maior frequência. Para a pesquisadora, o tratamento observado nas cartas dependia do destinatário visado, obedecendo a algumas regras - afetuoso ou formal -, de acordo com o parentesco e a intimidade com aquele para quem se escrevia: avô, tio, primo, pai, ou um parente distante, que se conhecia muito pouco. Um exemplo de diálogo informal, mais respeitoso, é encontrado em uma carta de 8 de março de 1940, escrita em Petrópolis, quando Didinha pedia desculpas pela letra:

Desculpem a minha letra que está péssima; é que comecei a carta hontem a noite, mas senti-me cansada e agora escrevendo da cama enquanto o maridinho se prepara para descer com Dr Pedro Paulo Paes de Carvalho. Mamãe continua em Rio Grandina de onde nos manda sempre boas noticias. Eu vou enviar a ela seu cartão, que por ela agradeço (Rio de Janeiro, 8 de março de 1940).

Percebe-se, neste fragmento, certa liberdade de expressão, mas com um mínimo de cuidado, condizente com as convenções sociais estabelecidas.

As cartas também são importantes fontes para se compreender a rede de sociabilidade em que se situam os correspondentes. Segundo Mignot: 
meio dela que as pessoas, mesmo distantes fisicamente, podem trocar ideais e afetos, construir projetos mútuos ou discutir planos opostos, estabelecer pactos ou polêmicas e organizar ações conjuntas (MIGNOT, 2002, p. 223).

O acervo, assim, representou um momento que permitiu descortinar a história de Didinha. Isto confirma quanto as diferentes categorias de materiais - carta, caderno, documento, foto - abriram possibilidades de cruzar informações e refletir sobre o que ocorria nas diferentes fases da vida da educadora, observando ainda a interação entre o indivíduo e a sociedade.

\section{Referências}

BOURDIEU, Pierre. O sociólogo e o historiador. Tradução Guilherme João de Freitas Teixeira. Belo Horizonte: Autêntica Editora, 2011.

CARVALHO, Astrogildes Delgado. Cadernos de Retiro. Petropolis,1953.

CASTRO, Celso. A trajetória de um arquivo histórico: reflexões a partir da documentação do Conselho de Fiscalização das Expedições Artísticas e Científicas no Brasil. Estudos Históricos, Rio de janeiro, n.36, p.33-42, jul./-dez. 2005.

CASTRO, Celso. Pesquisando em arquivos. Rio de Janeiro: Ed. Zahar, 2008.

CUNHA, Maria Teresa Sousa. Territórios abertos para a história. In: PINSKY, Carla Bassanezi; LUCA, Tania Regina. O historiador e suas fontes. São Paulo: Editora Contexto, 2009 a. 251.p.

CUNHA, Maria Teresa Sousa. Viver e escrever: cadernos e escritas ordinárias de um professor catarinense (século xx). Trabalho apresentado no XI Congresso Nacional de de Educação - EDUCERE, Curitiba, 2013. CUNHA, Maria Teresa Sousa. Viver e escrever: cadernos e escritas ordinárias de um professor catarinense (século xx) — 2013. In: CUNHA, Maria Teresa Sousa. (Org.). Uma biblioteca anotada: caminhos do leitor no acervo de livros escolares do Museu da Escola Catarinense (década de 20 a 60/século XX). Florianópolis: Imprensa Oficial do Estado de Santa Catarina; UDESC, $2009 \mathrm{~b}$.

CUNHA, Maria Teresa Sousa. No tom e no tema: escritas ordinárias na perspectiva da cultura escolar (segunda metade do século XX). In: BENCOSTTA, Marcus Levy Albino 
(Org.). Culturas escolares, saberes e práticas educativas: itinerários históricos. São Paulo: Cortez, 2007.

CUNHA, Maria Teresa Sousa. Diários íntimos de professores que duram. In: MIGNOT, Ana Chrystina; BASTOS, Maria Helena ; CUNHA, Maria Teresa S. (Orgs.). Refúgios do eu: educação, história, escrita autobiográfica. Florianópolis: Mulheres, 2000. p. 159-180.

FARGE, Arlete. O sabor do arquivo. São Paulo: Universidade de São Paulo, 2009.

GALVÃO, Walnice Nogueira; GOTLIB, Nádia Battella (Orgs.). Prezado senhor, prezada senhora: estudos sobre cartas. São Paulo: Companhia das Letras, 2000.

GIOVANAZ, Marlise Maria. Práticas de coleção: seleção e classificação dos restos do passado. Anos 90, Porto Alegre, n. 11, jul. 1999.

GOMES, Ângela Castro (Org.). Escrita de si, escrita da história. Rio de Janeiro: Editora FGV, 2004.

KOSSOY, Boris. Fotografia e história. São Paulo: Ateliê Editorial, 2001.

MAUAD, Ana Maria. Poses e flagrantes: ensaios sobre a história e fotografias. Niterói, Editora da Universidade Federal Fluminense, 2008.

MAUAD, Ana Maria. Na mira do olhar: um exercício de análise da fotografia nas revistas ilustradas cariocas na primeira metade do século XX. Anais do Museu Paulista, São Paulo, N. Sér. v.13, n. 1.p.133174, jan./-jun. 2005.

MIGNOT, Ana Chrystina Venancio; LEITE FILHO, Aristeo. A criança tem necessidade de expansão física: recomendações e prescrições de uma educadora para o jardim de infância. Cadernos de História da Educação, v. 10, n. 2, p.189-202, jul./dez. 2011.

MIGNOT, Ana Chrystina Venancio; LEITE FILHO, Aristeo. (Org.). Cadernos à vista. Escola, memória e cultura escrita. Rio de Janeiro: Eduerj, 2008.

MIGNOT, Ana Chrystina Venancio; LEITE FILHO, Aristeo. Baú de memórias, bastidores de história: o legado pioneiro de Armanda Álvaro Alberto. Bragança Paulista: EDUSF, 2002.

MIGNOT, Ana Chrystina V; BASTOS, Maria Helena Cunha; Maria Teresa. S. (Orgs.).

Refúgios do eu. Florianópolis: Mulheres, 2000. 
Recebido em 10/12/2014 Aprovado em 30/03/2015

Universidade do Estado de Santa Catarina - UDESC Programa de Pós-Graduação em História - PPGH Revista Tempo e Argumento Volume 07 - Número 14 - Ano 2015 tempoeargumento@gmail.com 